\title{
Criterios \\ La gestión de los paisajes culturales de montaña. Impacto Arqueológico en el Plan Eólico de Galicia
}

María Cacheda Pérez

Laboratorio de Arqueoloxia da Paisaxe. Instituto de Estudos Galegos Padre Sarmiento. CSIC-XuGa

\section{Resumen}

Estea articulo intenta ofrecer ejemplos del tipo de paisajes arqueológicos de montaña gallegos afectados por el Plan Eólico Estratéxico de Galicia y de los modos en que se ha producido la gestión de los mismos a la hora de abordar los correspondientes Estudios de Impacto Arqueológico. Se postula una gestión del paisaje arqueológico que abarca desde la fase de diseño del parque, con el objetivo de prevenir futuros impactos, hasta la fase de construcción del mismo, en donde se aprecia la evolución de los distintos criterios utilizados a través de los años, sobre todo en la estrategia de corrección aplicada, orientada a la integración del parque eólico y el paisaje arqueológico.

\section{Palabras clave}

Plan Eólico Estratéxico de Galicia

Parque Eólico

Estudios de Impacto Arqueológico

Gestión

Estrategia de Corrección

Plan Global de Corrección

Evaluación de Impacto Ambiental

Paisaje cultural

Galicia

\section{Introducción}

La gestión de los paisajes culturales en los Estudios de Impacto Arqueológico (EsIArq en adelante), dentro de las Evaluaciones de Impacto Ambiental, implica actuaciones dirigidas a intentar mantener el paisaje con el fin de equilibrar las transformaciones inducidas en él por la evolución social y económica, que supone la integración de un paisaje moderno, un parque eólico, en un paisaje cultural de montaña, en concreto un paisaje en el que existen elementos prehistóricos.

El paisaje es ahora objeto de estudio arqueológico y, por lo tanto, hay que idear metodologías para gestionarlo y comunicarlo a la sociedad; ya no se estudian los elementos que han quedado fijados, que son perceptibles y son el resultado de las interrelaciones entre el hombre y el medio; hay que estudiarlos como un sistema coherente que haga posible una presentación de la rica realidad histórica que sintetiza un paisaje. Esta idea se refleja en los ejemplos propuestos en el texto, a través de las estrategias de corrección propuestas en los EsIArq.

El trabajo continuado en los EsIArq de los parques eólicos gallegos desde el año 1995 nos demuestra que existen pautas para definir diferentes paisajes culturales en las zonas montañosas de Galicia. A través de las prospecciones arqueológicas de dichos estudios podemos distinguir al menos cinco tipos (de los cuales tres se encuentran ejemplificados más adelante), definidos en Amado et al., 2003: 57-59: paisajes cazadores (áreas de actividad con industria lítica y abrigos desde el Epipaleolítico al Mesolítico), paisajes monumentales (túmulos y megalitos de la época Neolítica), paisajes domesticados (yacimientos habitacionales, aldeas, de la Edad del Bronce), paisajes con arte (petroglifos de la Edad del Bronce) y paisajes fortificados (castros de la Edad del Hierro). Los paisajes fortificados y los domesticados son los menos representados en los EsIArq.

A través de la estrategia de corrección, de la que hablaremos a continuación, se gestionan los distintos paisajes culturales localizados en el trabajo de campo previo al EsIArq para la futura realización de un parque eólico. Esta estrategia (como veremos en los ejemplos propuestos) está dirigida a intentar proteger dichos paisajes; superando el aislamiento y la descontextualización de las estrategias centradas en una gestión individual para cada uno de los diferentes yacimientos arqueológicos.

\section{Estrategia de corrección}

Las medidas correctoras son las encargadas de evitar en lo posible la afección que el proyecto de un parque eólico generará, una vez construido, sobre los paisajes culturales. Se definen (Amado et al., 2003: 75) como todas aquellas propuestas o dispositivos de tipo formativo, así como las intervenciones activas concretas 


\section{Criterios}

La gestión de los paisajes culturales de montaña.

Impacto Arqueológico en

el Plan Eólico de Galicia

\section{María Cacheda Pérez}

que se consideran necesarias para evitar, prevenir, mitigar, compensar o restituir los efectos negativos de un impacto, así como las posibles alternativas existentes a las condiciones inicialmente previstas en el proyecto.

Las ideales son las que tienen un carácter preventivo, ya que la mejor forma de corregir un impacto es evitar que se produzca.

Las distintas fases de una estrategia de corrección de impacto deben ser previstas y diseñadas en el Plan Global de Corrección. Son las fases de diseño, la de replanteo, ejecución, seguimiento de la restitución de los terrenos y, finalmente, la vigilancia en la fase de explotación del parque eólico. Hay que diseñarlas y organizarlas teniendo en cuenta la problemática de cada una de estas fases, y deben contemplar las medidas necesarias que habrá que adoptar a lo largo de la ejecución del proyecto. Este plan debe formar parte del Informe Final del Estudio de Impacto Arqueológico, que se adjuntará al Estudio de Impacto Ambiental correspondiente.

Dependiendo del carácter de las medidas a adoptar, (en Amado et al., 2003: 75-81), se clasifican en:

> Medidas Preventivas o Protectoras: son las actuaciones que intentan evitar la aparición de un impacto mediante la modificación de los elementos o procesos definitorios de la actividad proyectada. Tienen un carácter puntual sobre elementos conocidos y son aquéllas que suponen modificaciones en el proyecto de obra y la señalización física de elementos o zonas a proteger. Las principales son: áreas de cautelas arqueológicas, que establecen prevenciones sobre un elemento o conjunto de elementos del patrimonio, señalizaciones de los elementos a proteger antes de la ejecución del proyecto, modificaciones del trazado durante el diseño del proyecto y el seguimiento y control arqueológico de la obra a realizar.

> Medidas Paliativas: son actuaciones que no evitan que el impacto se produzca, pero disminuyen su intensidad y su grado de afección. Actúan en los distintos elementos en los que se detectan impactos recuperables y sobre restos no conocidos con anterioridad a la ejecución del proyecto, atenuando, corrigiendo o modificando acciones y efectos de la ejecución del mismo. Se llevarán a cabo antes o durante el seguimiento arqueológico de las obras (estrategia integral de los trabajos de corrección de impacto) y un ejemplo serían los traslados de elementos estructurados muebles para evitar su destrucción.

$>$ Medidas Compensatorias: se proponen sobre todo en elementos con impacto crítico y severo (en algunos casos). Implican la destrucción del registro arqueológico en distintos grados; suelen ser intervenciones que suponen la destrucción o alteración importante de ese registro (excavaciones, sondeos...). Este tipo de medidas, recomendadas a veces en alguno de los proyectos estudiados, no se llegaron a aplicar, ya que se intentan evitar por todos los medios, realizando cambios en el diseño del proyecto, por el elevado coste que supondría para el promotor un tipo de actuación de estas características.

\section{Ejemplos}

A continuación se exponen ejemplos de tres Estudios de Impacto Arqueológico, en los que se aplicaron diferentes estrategias de corrección en función de las características del Paisaje Cultural afectado, y que ejemplifican tres casos diferentes.

Primero un modelo de aplicación de medidas correctoras preventivas, basado en un diálogo constante con la empresa encargada de elaborar el proyecto: el Parque Eólico de Graiade (Porto do Son, A Coruña); en segundo lugar, exponemos una estrategia de corrección basada en la aplicación de medidas correctoras paliativas, en la ampliación para el Parque Eólico de Soán (Muras y 0 Valadouro, Lugo); por último, medidas correctoras compensatorias, aplicado en el Parque Eólico de Fonsagrada (A Fonsagrada y Ribeira de Piquín, Lugo).

\section{Parque Eólico de Graiade}

Un ejemplo representativo y actual de un Estudio de Impacto Arqueológico con una estrategia de corrección basada en la aplicación de medidas correctoras preventivas es el del Parque Eólico de Graiade (Porto do Son, A Coruña), realizado entre julio de 2003 y febrero de 2004. A través de un diálogo continuo con la empresa promotora (Jealsa Rianxeira S.A.), encargada de elaborar el proyecto de construcción, se pudieron evitar, desde un principio, futuros impactos y, a la vez, intentar respetar el paisaje cultural de la zona a través de la preservación de los elementos que lo componían.

El diseño provisional propuesto para el parque presentaba un total de 29 aerogeneradores distribuidos en varias alineaciones, además de la subestación y de los viales (algunos reutilizados de caminos existentes). Con estos datos proporcionados por la empresa, y a través de una cartografía de la zona que se iba a estudiar, se diseñaron las diferentes fases de trabajos arqueológicos que se iban a ejecutar.

Las fases a las que nos referimos son, en general, las comunes a cualquier estudio de impacto, y se llevaron a cabo en los tres ejemplos citados: un vaciado de la bibliografía existente y otro del Inventario Arqueológico de Galicia que se encuentra en el Servicio de Arqueología de la Dirección General de Patrimonio Cultural (DXPC en adelante), la visita a los ayuntamientos afectados para compro- 
1. Roca con podomorfo

2. Roca grabada con cazoletas y cruces inscritas en cuadrados

3. Roca grabada con cazoleta y laberinto en primer término

bar si en sus Planes generales de urbanismo o Normas Subsidiarias tienen alguna figura de protección propia para elementos de carácter histórico, arqueológico o etnográfico y una prospección arqueológica extensiva del ámbito que ocupará el parque eólico.

Antes de realizar el trabajo de campo se documentaron dentro del poligono de estudio un castro, cinco túmulos, trece petroglifos y un elemento etnográfico (un cruceiro). Muchos de estos elementos se iban a ver afectados en su entorno de protección legal (entorno fijado por la DXPC en 200 m para los yacimientos arqueológicos y en $50 \mathrm{~m}$ para los etnográficos) por el futuro parque (Fotos 1 y 2).

A continuación se realizó una prospección arqueológica extensiva de la poligonal que ocupaba el parque eólico, de cuyos resultados se informó a la empresa contratante. Se ubicaron los yacimientos ya conocidos con tecnología GPS y se documentaron algunos nuevos, concretamente dos petroglifos. Se realizó una primera diagnosis del impacto arqueológico, recomendando una serie de cambios en el diseño del proyecto por afectar al área de protección de los yacimientos localizados, diagnosticando en alguno de los casos impactos críticos y severos (Foto 3 ).

Con una cartografía nueva y detallada, proporcionada por la empresa después de analizar los resultados de los que se les había informado mediante el estudio realizado con anterioridad, se comprobó que se habían eliminado varias alineaciones de aerogeneradores (concretamente en la zona $\mathrm{N}$ y W del trazado) y el nuevo proyecto constaba de 13 , situados en el centro del poligono estudiado; así se evitaban esos impactos irreversibles que se habían diagnosticado y se respetaban los entornos de protección legal de casi todos los yacimientos (el nuevo diseño sólo afectaba al entorno de dos petroglifos). Se realizó entonces una prospección arqueológica intensiva, que dio como resultado la localización de dos petroglifos más y un túmulo. Se informó a la empresa de estos nuevos hallazgos ya que uno de los yacimientos estaba afectado directamente por la construcción de la subestación y se cambió la ubicación de la misma. A continuación se hizo la correspondiente diagnosis de impacto y, por último, se diseñó el Plan Global de Medidas Correctoras que se llevarían a cabo en la fase de construcción.

La estrategia de corrección basada en el diseño de medidas correctoras de carácter preventivo fue la siguiente:

$>$ Se establecieron áreas de exclusión adaptadas a los perímetros de los yacimientos arqueológicos documentados, que se reflejarían en la futura cartografía manejada por los operarios encargados de ejecutar el parque eólico.

> Sería necesario llevar a cabo el balizado, con material no perecedero (estacas de madera), restituyéndolo si fuese preciso, del perímetro del túmulo documentado.
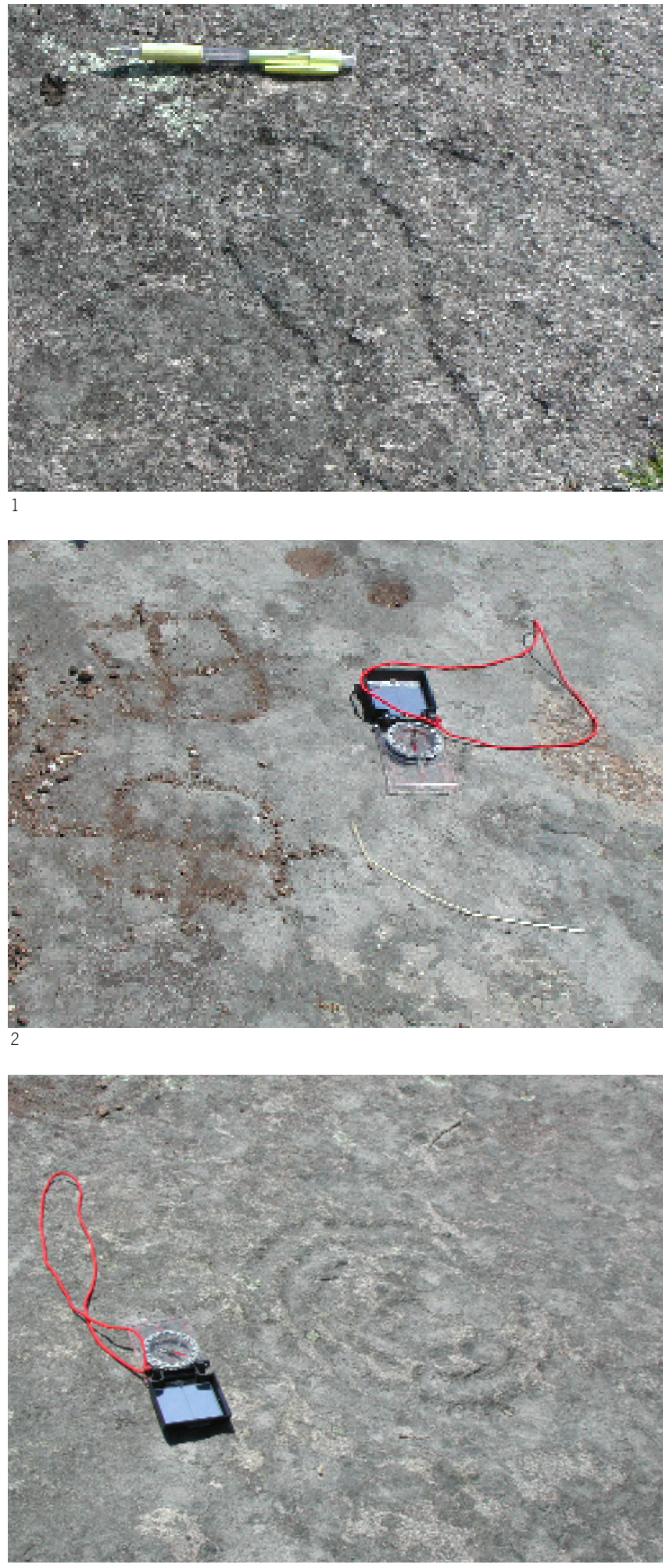

3 


\section{Criterios}

La gestión de los paisajes culturales de montaña.

Impacto Arqueológico en

el Plan Eólico de Galicia

\section{María Cacheda Pérez}

> Se realizaría el control y seguimiento arqueológico general de las obras, desde su comienzo hasta la fase final de restitución de los terrenos, que sería especialmente exhaustivo dentro de los entornos de protección de las entidades documentadas.

Aunque se logró salvaguardar uno de los paisajes culturales arqueológicos documentados en una de las zonas afectadas en un principio por el proyecto (concretamente se eliminó la alineación de la parte $W$ ), comprendida por varios yacimientos arqueológicos de distintas épocas, las medidas correctoras aplicadas finalmente se encargaron de proteger los elementos arqueológicos ante la inminente construcción del parque eólico.

\section{Ampliación para el Parque Eólico de Soán}

Un ejemplo con una estrategia de corrección aplicando medidas paliativas lo tenemos en el Estudio de Impacto Arqueológico para la ampliación del Parque Eólico de Soán (Muras, O Valadouro en la provincia de Lugo), realizado en septiembre del año 2000. El parque contaría con 29 aerogeneradores distribuidos en cuatro líneas, el vial que comunica dichos aerogeneradores, la zanja para cableado que transcurre paralela a éste, una subestación y un vial de acceso al parque que se realizaría desde la infraestructura viaria existente, desde la que saldrían los viales internos para acceso a los aerogeneradores, que tendrían una anchura aproximada de $4 \mathrm{~m}$.

Se llevaron a cabo las fases previas al trabajo de campo, a fin de recabar toda la información sobre la zona donde se iba a construir el parque; también se llevó a cabo un análisis de los componentes del proyecto que permitiera identificar aquellos agentes, factores de afección y acciones que pudieran ocasionar afecciones sobre el medio y, en concreto, sobre los elementos integrantes del Patrimonio Arqueológico y Etnográfico. A continuación se llevó a cabo la prospección arqueológica orientada hacia el descubrimiento de yacimientos de naturaleza tanto visible como invisible.

Todos estos estudios previos dieron como resultado la localización en el campo de dos zonas arqueológicas con restos de material antrópico: la Zona de Campelo y la Zona de Porto do Río.

La Zona de Campelo está formada por un amplio rellano, en una dorsal de estribación que sale en dirección SE desde la divisoria principal de la sierra, en concreto desde Chao de Lamoso. Es una amplia zona de cabecera de numerosos arroyos, que conforman brañas. Se encuentra a una altitud entre 700 y 800 m. En ella se han localizado numerosos puntos con material lítico tallado en superficie, distribuidos a lo largo de todo el rellano (Foto 4).

La Zona de Porto do Río está formada por un rellano, de menores dimensiones que el de Campelo, en una dorsal de estribación que
4. Zona de Campelo, vista general

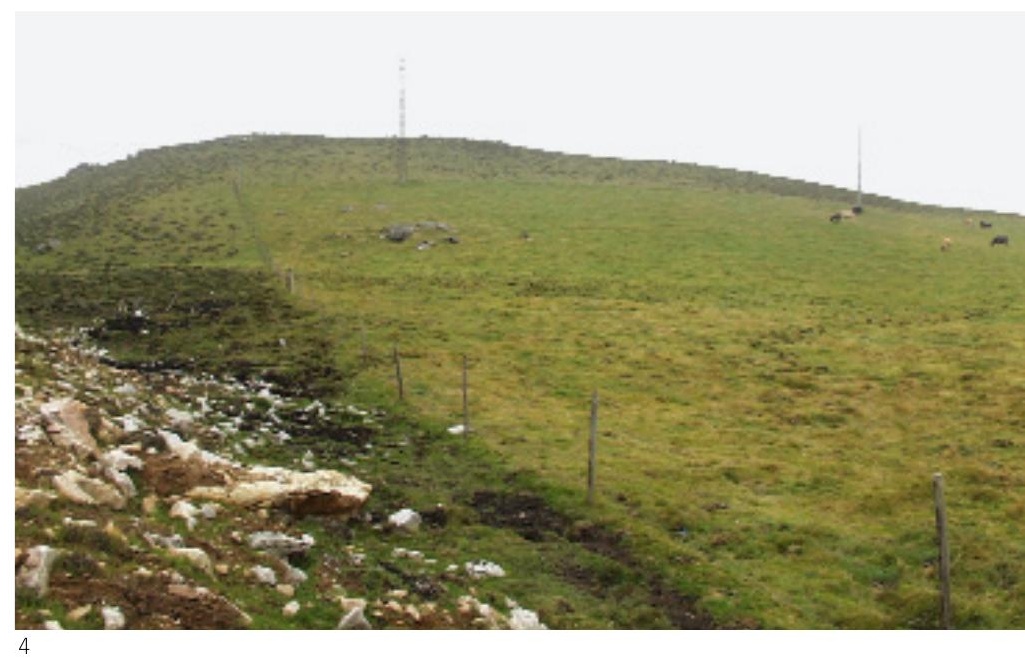

sale en dirección SE desde la divisoria principal de Serra do Xistral, en concreto desde Chao de Lamoso. Este rellano se encuentra perfectamente delimitado por varios arroyos que descienden por la ladera $\mathrm{E}$ de la divisoria. Tiene una altitud entre 750 y 800 m. En esta zona se ha localizado un yacimiento adscribible al Paleolítico Superior/Epipaleolítico, un abrigo en paragneis y gran cantidad de material lítico tallado, distribuidos a lo largo del rellano. Se trata de un yacimiento al aire libre evidenciado por el registro de diversos puntos con industrias líticas elaboradas en cristal de roca y cuarzo fundamentalmente. Desde el punto de vista geográfico ocupa un pequeño espolón con forma aplanada en la cima y un afloramiento a cuyo alrededor se dispone el material lítico. No obstante, las industrias se extienden también por las laderas W y S del espolón. El yacimiento se ubica en un punto estratégico desde el que se controla una cañada al S y, muy próxima (hacia el W), se sitúa el área de cabecera de un arroyo. Además, como hemos dicho, se documentó en esta zona un pequeño abrigo en paragneis, de aproximadamente $6 \mathrm{~m}$ de largo por $1 \mathrm{~m}$ de alto, que está emplazado en el área de cabecera de un arroyo y tiene una plataforma delantera fácilmente ocupable. Está emplazado en la parte final de la ladera de la dorsal de estribación que sale en dirección E-W desde Chao de Lamoso, en la cabecera de un arroyo (Foto 5)

A continuación, una vez realizado el inventario, se llevó a cabo la valoración de impacto que generaría la construcción del parque en las dos zonas documentadas, teniendo en cuenta una serie de criterios relacionados con los dos aspectos fundamentales del estudio: el proyecto y el inventario. Los impactos se consideraron severos. Las razones que justificaron el diagnóstico fueron:

$>$ La cantidad de material recogido y la variedad y calidad del mismo. $>$ La densidad existente, que se sitúa por encima de los parámetros que permiten diferenciar entre los restos de un área de actividad prehistórica de un yacimiento in situ 0 in loco. 


\section{Criterios}

La gestión de los paisajes culturales de montaña.

Impacto Arqueológico en

el Plan Eólico de Galicia

\section{María Cacheda Pérez}

materias primas, un tramo del Camino de Santiago asturiano y dos hospitales antiguos: uno en ruinas del S. XIV y otro que aún se conserva del S. XVI, vinculados ambos al Camino.

Se llevó a cabo la valoración del impacto de los diferentes elementos de la obra sobre los yacimientos arqueológicos y elementos patrimoniales de los que se conocia su ubicación exacta, ya que de 7 túmulos no se sabía con exactitud su localización, sino sólo la zona en que se encontraban (gracias a las diversas fuentes bibliográficas consultadas, en concreto unas prospecciones realizadas por Felipe Criado en 1987) y que, en el año de realización del estudio, no se pudieron localizar por la espesa vegetación que había crecido en esos lugares.

Los impactos fueron considerados severos y moderados en casi todos los casos, ya que el proyecto irrumpía en las áreas de protección legal, establecidas en 200 metros por la Ley de Patrimonio Cultural de Galicia, de los diferentes elementos inventariados. La estrategia de corrección tuvo mucho que ver con este factor. En principio se basó en medidas correctoras preventivas:

> Se establecieron ocho áreas de cautela efectiva en torno a los lugares donde supuestamente se emplazaban túmulos no localizados durante la prospección debido a la densa vegetación que cubría las áreas donde se encontraban, pero de los que se tenía conocimiento de su existencia, así como dos puntos en los que la zanja para cableado cortaría el Camino Primitivo a Santiago. Estas cautelas figurarian en la cartografía empleada durante la obra, igual que las siguientes (Foto 7).

> Se definieron también siete áreas de cautela preventiva en zonas en las que existían grupos más o menos numerosos de túmulos y que, por lo tanto, eran susceptibles de albergar evidencias arqueológicas vinculadas a éstos y no visibles en superficie sin una remoción del terreno: fosas, estructuras o cultura material mueble, frecuente en espacios entre túmulos y que responden a áreas de actividad doméstica, ritual o cultural del entorno de los conjuntos tumulares, o del paso del Camino de Santiago por la zona.

> En la fase de replanteo se verificarian las áreas de cautela definidas con anterioridad y se señalizarian los yacimientos más próximos al lugar donde se desarrollaban las obras (Foto 8).

> Ya en fase de obra, se realizaría un control y seguimiento arqueológico por un equipo de arqueólogos, que sería más exhaustivo en las áreas de cautela efectiva, en el entorno general de los yacimientos y estructuras documentados, prestando especial atención dentro de las áreas de cautela preventiva y controlando la restricción del tráfico rodado en las proximidades de algunos yacimientos tumulares y del Camino de Santiago.

Como novedad, en fase de obra también se llevaría a cabo una puesta en valor de los yacimientos arqueológicos de la Serra do
Hospital como medida correctora compensatoria, por construirse el futuro parque en el ámbito directo de los yacimientos sin respetar las áreas de protección legales. Esta decisión fue acordada entre la empresa promotora y el Servicio de Arqueología de la DXPC debido a la inminente destrucción de los yacimientos por las labores agrícolas de la zona. Con esto se conseguía restringir el uso del suelo que pasaba a formar parte del ámbito eólico y así proteger los túmulos y además garantizarles un futuro con la puesta en valor. En el Estudio de Impacto se realizó un esbozo de dicho plan, pero el proyecto detallado y definitivo se presentó en febrero del año 2004, y está prevista su realización en el verano de 2005. La estrategia de recuperación que se propuso fue:

> Una intervención blanda que permitiese poner en valor los restos arqueológicos sin necesidad de realizar grandes inversiones ni acometer acciones agresivas sobre el patrimonio.

> Plantear una aproximación territorial que reintegrase los monumentos al entorno y evocase el paisaje ritual y funerario del que originalmente formaron parte esos yacimientos tumulares.

Para ello se llevarán a cabo una serie de actuaciones, como medidas compensatorias generales, destinadas a integrar la explotación del parque con el rico patrimonio arqueológico, histórico y paisajístico de la zona:

> Completar la prospección arqueológica y etnográfica en la fase de construcción de la obra.

> Roza de 21 monumentos tumulares y su entorno y su revegetación (Foto 9).

> Restitución volumétrica de la masa tumular de al menos 13 de los túmulos documentados.

> No se descarta la posibilidad de acometer algún tipo de intervención puntual, como es la limpieza del Hospital Vello y del Real Hospital de Montouto.

> Se llevará a cabo la recuperación del entorno y la limpieza del Camino de Santiago en las zonas expropiadas para construir el parque.

$>$ Labores periódicas de limpieza y de acondicionamiento de accesos y entorno, supervisadas por técnicos arqueólogos.

Las actuaciones a realizar en el conjunto tumular se pueden agrupar en:

> Actuación de limpieza, documentación, aportes de tierra y control de aperturas de viales, que se realizarán en la primera fase de construcción del parque (Foto 10). 


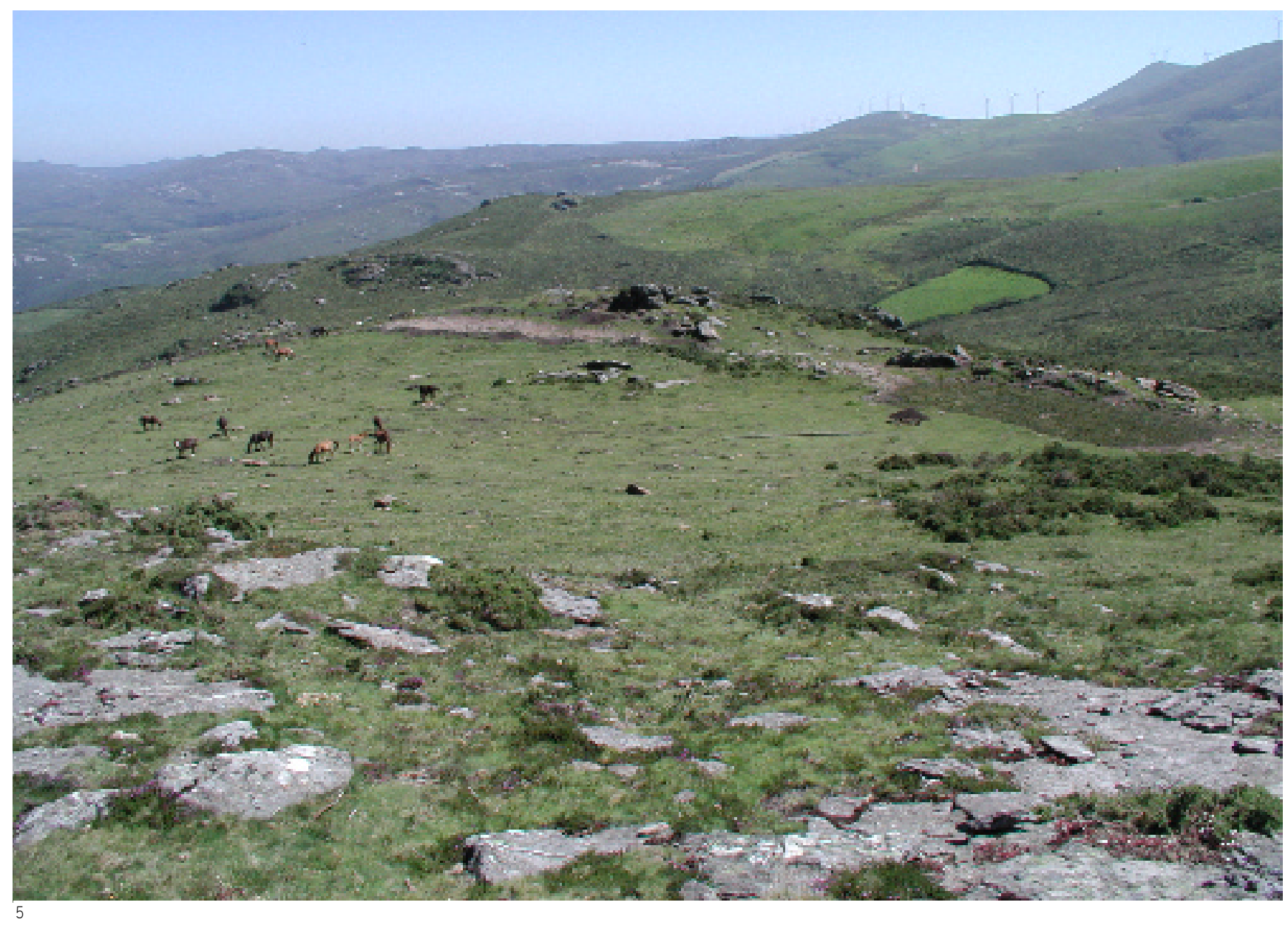

> Actuaciones de señalización y revegetación que se realizarán en una última fase paralelamente a la construcción de un aula didáctica del parque.

> Acciones futuras: excavación y consolidación.

\section{Valoración del paisaje cultural: conclusiones}

En cuanto al Parque Eólico de Graiade, en su zona W, en la que en un principio se habia proyectado una alineación de 9 aerogeneradores con sus correspondientes viales, se decidió suprimir dicha alineación. Así se pudo salvaguardar (de momento) un espectacular paisaje arqueológico de montaña gallego, producido por la actividad humana en la prehistoria que ha perdurado hasta el presente teniendo en cuenta la integración de las nociones de territorio, percepción individual, percepción social, acciones y transformaciones naturales, acciones y transformaciones antrópicas (factores ya proclamados en la Convención Europea del Paisaje), factores interrelacionados entre sí, con una idea de paisaje como relación dinámica en evolución.

En concreto, la zona que se respetó está formada por una sucesión de varias zonas altas compuestas de montes y montículos de entre 220 m y 350 m de altura, dispuestos en dirección SE-NW (Monte Espiñeiro, Monte Esperoi y Portela de Gourís), delimitados al W por el Océano Atlántico. Aparece también un regato estacional y una zona dominada por una vaguada (al E) con una braña alveolar circular de unos $50 \mathrm{~m}$ de diámetro llamada Lagoa de Cabrais. Se trata de una zona con varios yacimientos de diversos tipos de la Prehistoria: un yacimiento tumular adscribible al Neolítico (Mámoa de Cabrais), varias estaciones de petroglifos seguramente de la Edad del Bronce, Beira da Costa (cuatro rocas grabadas) y Monte Espiñeiro (otras cuatro rocas grabadas); y, posiblemente, alguna Medieval (Monte Gouris); además de un castro de la Edad del Hierro con ocupación medieval (Castro da Lagoa). Todas estas características mencionadas hacen de este territorio un lugar con fuerte actividad antrópica durante toda la prehistoria y parte de la Edad Media.

Los yacimientos se disponen ocupando distintas posiciones en torno a la braña controlando así distintas zonas de la misma. Se sitúan en puntos desde los que se domina el terreno circundante y destacan notoriamente sobre él, correlacionados con signos naturales visibles: rocas, accidentes del terreno, brañas, vías de tránsito que los unen...

En cuanto a los trabajos arqueológicos efectuados en la ampliación para el Parque Eólico de Soán, han servido para constatar la importancia del lugar de 0 Porto do Río como área de actividad paleolítica dentro del marco de la sierra de Xistral. Su ubicación en un extenso llano ubicado en el tramo medio de una dorsal que comunica las cumbres de la sierra con los valles interiores, dominando el área de cabecera de un arroyo, responde a un tipo de emplazamiento que parece que ha sido ocupado de forma recurrente por las sociedades cazadoras-recolectoras de dicho período. Sin embargo, las bajas densidades de artefactos registradas durante los trabajos arqueológicos efectuados apuntaron a que este llano no fue objeto de una ocupación estable del tipo de la registrada en otros puntos de la misma sierra. No obstante, hay que tener en cuenta que el yacimiento ha sido 


\section{Criterios \\ La gestión de los paisajes culturales de montaña. \\ Impacto Arqueológico en \\ el Plan Eólico de Galicia \\ María Cacheda Pérez}

objeto de múltiples agresiones no relacionadas con la construcción del parque (como actividades forestales o agricolas) que han supuesto el desmantelamiento de los terrenos hasta la roca base en la mayor parte de su extensión.

La existencia de numerosos prismas de cuarzo y cristal de roca, no sólo en esta dorsal sino también en las colindantes, la presencia de numerosos cantos rodados de origen fluvial posiblemente trasladados alli desde los arroyos cercanos, unido a las categorías tecnotipológicas predominantes en la colección recuperada, apuntan a que este lugar constituyese una importante fuente de aprovisionamiento de materias primas. Los restos localizados estarían entonces ligados a actividades relacionadas con esta función.

Como balance preliminar de los trabajos se pudo avanzar que se cumplieron los objetivos especificados en el correspondiente proyecto de actuación. En resumen, $\mathrm{M}^{\mathrm{a}}$ del Mar López Cordeiro (2003: 22), directora de estos trabajos arqueológicos Ilegó a la conclusión de que:

1. El lugar de Porto do Río debe ser entendido no de forma aislada sino como parte de un área de mayor envergadura donde las sociedades paleoliticas desarrollaron sus actividades. Es imprescindible superar el tratamiento punto a punto de la distribución arqueológica del material recuperado para ver que dichos puntos forman parte de unidades más extensas, áreas de actividad prehistórica.

2. El yacimiento no se conserva in situ, parece que los materiales arqueológicos han sido desplazados de su posición original o removidos en el sitio (dependiendo del sector concreto en el que nos situemos). El lavado y encharcamiento del suelo y en algunos casos la dinámica de ladera es la responsable de este extremo. Este punto viene avalado por los resultados obtenidos durante la inspección de perfiles de todo el espacio y por las orientaciones y buzamientos de las piezas registradas en los sectores de excavación. Podemos hablar de industrias in loco ya que lo que parece claro es que el transporte ha sido mínimo y local.

3. Este lugar pudo haber funcionado como fuente de aprovisionamiento de materias primas, como así lo avalan las características del registro arqueológico recuperado.

La intervención en el Parque Eólico de Fonsagrada permite mostrar en la práctica la conjunción entre el parque eólico y el medio natural, siendo ésta la herramienta clave en la compatibilización de un plan industrial y la conservación y promoción del patrimonio directamente afectado por él. Teniendo en cuenta que la problemática patrimonial y arqueológica es uno de los factores críticos en el diseño y construcción de los parques eólicos y que, en ocasiones, constituye el principal riesgo al que se enfrentan las
6. Sondeos arqueológicos en Porto do Río

7. Túmulo balizado en primer término; al fondo Hospital Real de Montouto ubicado en el Camino de Santiago

8. Túmulos señalizados en la fase de obra del parque eólico

Evaluaciones de Impacto Ambiental, parece doblemente oportuno recuperar de forma activa los monumentos tumulares y aprovechar para ejemplificar los esfuerzos dedicados a resolver esta temática por todos los agentes implicados: promotores, constructoras, Dirección General de Patrimonio Cultural, Consellería de Industria, Consellería de Medio Ambiente y asistencias técnicas arqueológicas.

Las actuaciones que se propusieron para la recuperación de la necrópolis forman parte de un proyecto museográfico más amplio que engloba también su señalización, la creación de rutas, una exposición permanente que se realizará en la primera planta del edificio de la subestación del parque eólico que funcionará como aula didáctica de la necrópolis, la publicación de guias, etc.

El estudio sobre la localización y delimitación de paisajes culturales tumulares aporta una buena base para comprender, dentro del espacio en torno a los monumentos, los factores que determinan su emplazamiento. Es preciso no tratar de forma individual cada túmulo sino que hay que integrar en una zona las mámoas que forman un grupo: una necrópolis, incorporando el área de visibilidad inmediata o la cuenca o braña próxima a los túmulos y hacia la que se dirige la visibilidad de éstos, ya que esa zona puede llegar a contener un asentamiento asociado. La Serra do Hospital (donde se localizan la mayoría de los yacimientos integrados en el futuro parque eólico) es un buen ejemplo de paisaje cultural monumental localizado en los montes de Galicia, que es necesario preservar por su alto grado de significatividad patrimonial y por toda la información que nos ofrece sobre las sociedades prehistóricas constructoras de túmulos. Su gestión a través del Estudio de Impacto Ambiental y el Plan de recuperación de dicha sierra es un ejemplo a seguir por los promotores y empresas constructoras, por todas las posibilidades que ofrece a la hora de sociabilizar y potenciar económicamente la zona conjugando un paisaje antrópico contemporáneo con otro antrópico prehistórico.

La valoración del impacto sobre zonas arqueológicas de difícil definición espacial resulta complicado, aunque para ello tendremos en cuenta unos criterios básicos que nos ayuden a delimitar genéricamente los paisajes culturales con restos arqueológicos. Criterios basados en razones arqueológicas, morfológicas y arqueogeográficas (Amado el al., 2003: 59) y puestos en práctica a través del Estudio de Impacto de los tres Parques Eólicos que ejemplifican este texto. Nos referimos por ejemplo a la evidente agrupación de yacimientos formando conjuntos como necrópolis (es el caso del Parque Eólico de Fonsagrada), estaciones rupestres (Parque Eólico de Graiade) o áreas de acumulación de material arqueológico (Parque Eólico de Soán). Otros criterios podrían ser la definición del arco de visibilidad inmediata, la integración de la unidad fisiográfica sobre la que se emplazan los yacimientos 0 la ampliación del espacio delimitado hasta comprender la cuenca o braña situada en su proximidad. 

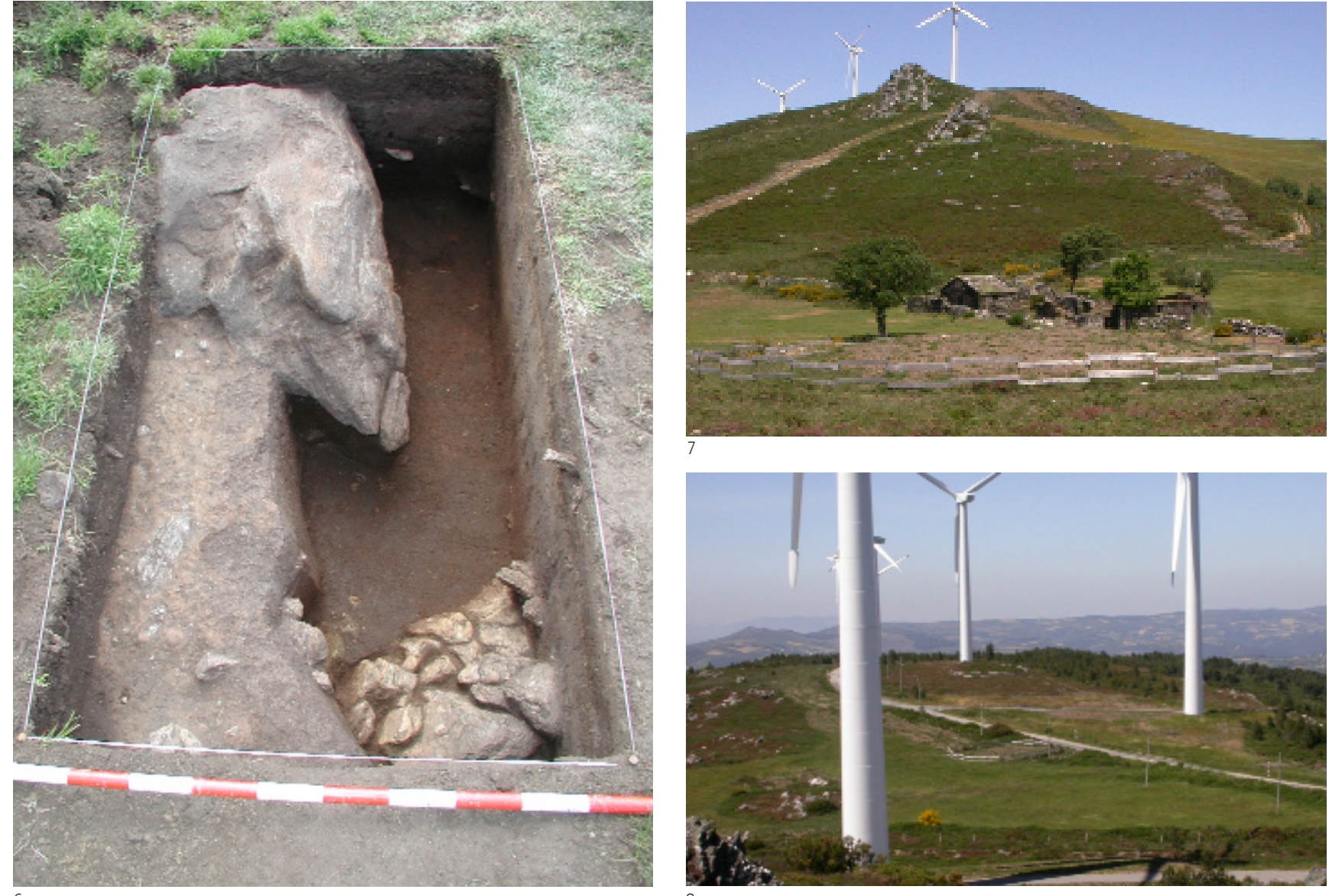

Se consigue superar poco a poco el estudio aislado de elementos que han quedado fijados de una u otra manera y que actualmente son perceptibles. El paisaje ya no se concibe como un marco espacial en el que ubicamos yacimientos arqueológicos, sino como una síntesis de las relaciones entre esos elementos a lo largo del tiempo.

La novedad en este tipo de estrategias de corrección es que se consigue que la afección que produce un proyecto de un parque eólico se aplique al paisaje, no a los yacimientos aisladamente, como se hizo en los primeros Estudios de Impacto Arqueológico (1995-1998).

El desarrollo de dichos estudios hace que los sistemas predictivos de localización de yacimientos se perfeccionen y permitan realizar estimaciones fiables sobre la existencia de éstos en zonas afectadas por los proyectos del Plan Eólico Estratéxico de Galicia ${ }^{1}$. Así, estas previsiones simplificarian el desarrollo de las estrategias de prospección y los costes implicados en la resolución de imprevistos de naturaleza arqueológica, permitiendo una maximización del trabajo y del conocimiento generado por una actuación de este tipo. El trabajo realizado constituye una prueba de la viabilidad de un programa de trabajo que emplea "la investigación básica como fundamento de una investigación de carácter aplicado" (Ayán y Amado, 1999: 83).

Los EslArq de los diferentes planes eólicos deben integrarse en un programa global de EIA e insistir en que su realización en un momento temprano y de un modo satisfactorio aportará ventajas prácticas y de rentabilidad a los proyectos industriales.

Dado que la normativa existente considera al Patrimonio Cultural y, por lo tanto, al Arqueológico, como uno de los factores que conforman el Medio Ambiente, se pretende realizar estos estudios aplicando un análisis y tratamiento integral de la problemática ambiental que incluya el factor arqueológico. Esto permitiría

llevar a cabo un tratamiento general de los Eslarq, lograr una perspectiva global e integradora para tratar como un conjunto el EIArq del Plan Eólico y facilitar la coordinación de actividades entre las distintas instancias: empresas promotoras, la Dirección Xeral de Patrimonio Cultural y arqueólogos.

A través de los ejemplos citados se afirma que la práctica de la EIA ha logrado importantes avances a la hora de corregir impactos sobre los elementos aislados que integran el Paisaje Cultural, generado a raíz de la ejecución de un parque eólico. En estos casos, la estrategia de corrección aplicada respeta los yacimientos por separado para que no se vean afectados físicamente por las futuras obras. Se logran avances: por ejemplo, en el Parque Eólico de Graiade se logró conservar una zona con un paisaje cultural importante alejando el proyecto; o en el Parque Eólico de Fonsagrada, con actuaciones específicas para la recuperación de una necrópolis formada por numerosos túmulos neolíticos. Sin embargo, este tipo de prácticas sólo permite paliar los impactos inherentes al diseño y ejecución de los proyectos, con lo que se necesita buscar una solución que permita evaluar impactos que se originen en las fases previas al proceso de planificación del proyecto, que logren tener en cuenta y respetar integramente estos paisajes culturales arqueológicos, de los que venimos hablando a lo largo de todo el artículo.

La Evaluación Ambiental Estratégica ${ }^{2}$ puede ser una opción interesante: evaluación ambiental de políticas, planes y programas durante su proceso de elaboración. Esta directiva tiene un carácter claramente preventivo y busca integrar las consideraciones ambientales con las económicas y sociales.

Su aplicación, presumiblemente, permitirá mejorar la evaluación de los impactos ambientales indirectos y debería servir para reducir el número de proyectos con características similares (en este caso, parques élicos), con vistas a fomentar un desarrollo sostenible. 


\section{Criterios \\ La gestión de los paisajes culturales de montaña. Impacto Arqueológico en el Plan Eólico de Galicia \\ María Cacheda Pérez}

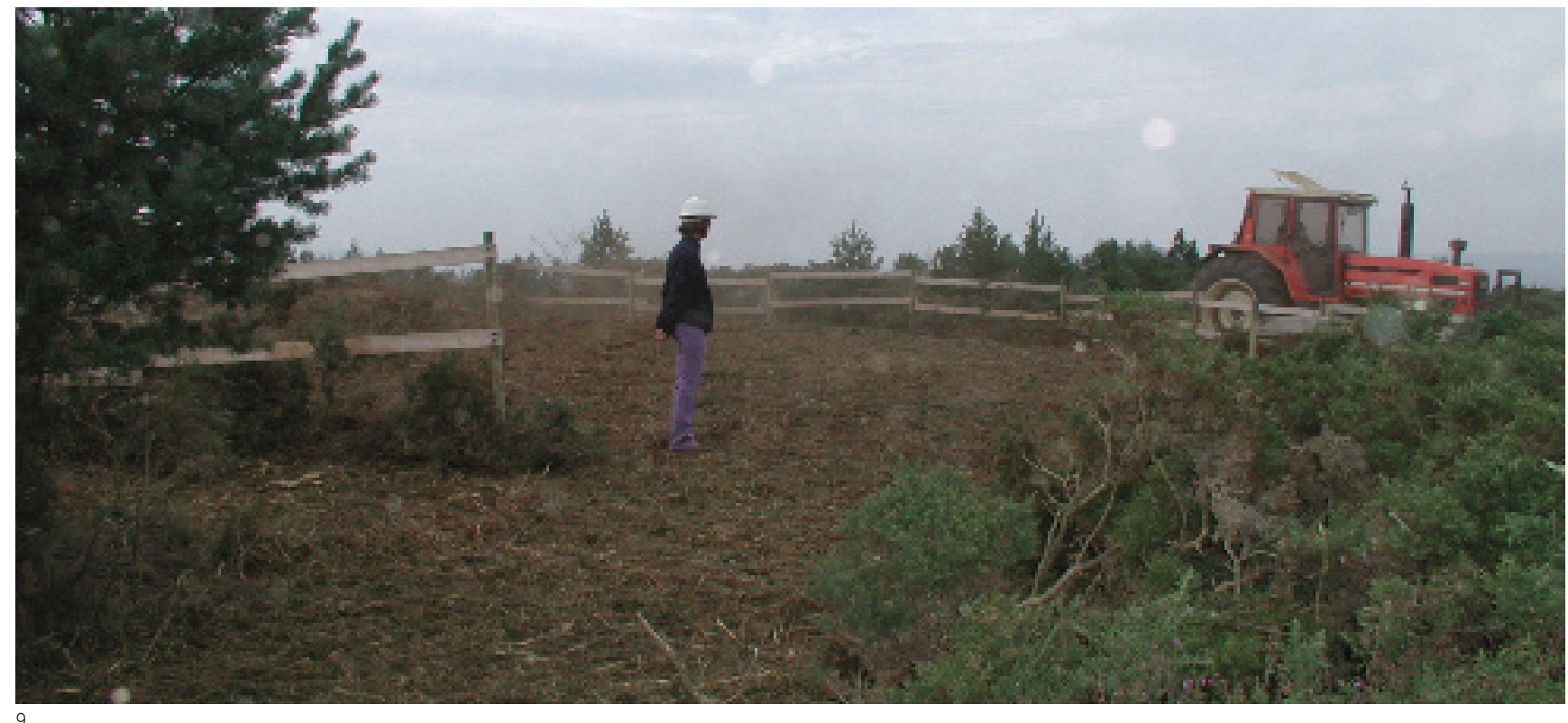

La Evaluación Ambiental Estratégica entiende la evaluación ambiental como un proceso formalizado, sistemático y con un enfoque global, a través del cual se intenta evaluar los impactos ambientales potenciales de una propuesta de plan o programa y sus alternativas. En este caso lo aplicariamos al Plan Eólico Estratéxico de Galicia, con el objetivo de permitir que se pueda mantener una perspectiva globalizadora sobre el Impacto Arqueológico de dicho plan, ofrecer un modelo común y presentar un plan unitario y criterios homogéneos para diseñar la Estrategia de Corrección de ese Impacto.

Notas

${ }^{1}$ El gran potencial eólico de Galicia llevó a establecer una normativa reguladora del aprovechamiento de la energía eólica: el Plan Eólico Estratéxico de Galicia. Este plan promueve, a su vez, distintos planes eólicos empresariales, la mayoría aprobados y en fase de ejecución.

${ }^{2}$ Directiva 2001/42/CE del Parlamento Europeo y del Consejo relativa a la Evaluación de los Efectos de Determinados Planes y Programas en el Medio Ambiente.

\section{Bibliografía}

AMADO REINO, X. (1999) Programas de Corrección de Impacto Arqueológico en la construcción de Obras Públicas. XXV Congreso Nacional de Arqueología. Valencia, 1999, p. 261-266

AMADO REINO, X.; BARREIRO MARTÍNEZ, B.; MARTÍNEZ LÓPEZ, Mª. C. (1998) Eva luación y Corrección de impacto arqueológico en obras públicas. Propuesta desde la Arqueologia del Paisaje. Traballos en Arqueoloxía da Paisaxe 2. Santiago de Compostela: LAFC, 1998

AMADO REINO, X.; CRIADO BOADO; F., BARREIRO MARTÍNEZ, D.; MARTÍNEZ LOPEZ, Ma. C. (2003) Especificaciones para una gestión integral del impacto desde la Arqueologia del Paisaje. Traballos de Arqueoloxía e Patrimonio 26. Santiago de Com- postela: Laboratorio de Patrimonio, Paleoambiente e Paisax, (IIT, USC), Unidade Asociada ao Laboratorio da Arqueoloxía da Paisaxe do IEGPS, (CSIC-XuGa), 2003

BARREIRO MARTíNEZ, D. (2000) Evaluación de impacto arqueológico. Criterios e Convencións en Arqueoloxía da Paisaxe 14. Santiago de Compostela: LAFC, 2000.

BARREIRO MARTíNEZ, D. (2002) Un modelo de estudio de impacto arqueológico. I Congreso de Ingenieria Civil, Territorio y Medio Ambiente. Vol. I, p. 481-490

BARREIRO MARTÍNEZ, D.; VILLOCH VÁZQUEZ, V. (1997) Un modelo de Evaluación de Impacto Arqueológico: El Parque Eólico de Careón. Criterios e Convencións en Arqueoloxía da Paisaxe 1. Santiago de Compostela: LAFC, 1997

BARREIRO MARTÍNEZ, D.; VILLOCH VÁZQUEZ, V.; CRIADO BOADO, F. (1999) El desarrollo de tecnologias para la Gestión del Patrimonio Arqueológico: hacia un modelo de Evaluación de Impacto Arqueológico. Trabajos de Prehistoria, n 56, p. 13-26

CACHEDA PÉREZ, M. (2002) La Arqueologia en el Plan Eólico de Galiza: Estudos de Evaluación de Impacto Arqueológico. Trabajo de Investigación inédito, depositado na Facultade de Xeografia e Historia de Santiago de Compostela

CACHEDA PÉREZ, M. (2003) Parque Eólico de Graiade, Estudio de Impacto Arqueolóxico, Avance de Informe. Inédito, depositado en la DXPC

CACHEDA PÉREZ, M. (2004) Arqueologia Aplicada: Sintesis de resultados en la gestión del impacto del Plan Eólico de Galiza (1995-2002). Arqueología Espacial (en prensa)

CACHEDA PÉREZ, M. (2004) Parque Eólico de Graiade, Estudio de Impacto Arqueolóxico, Memoria Técnica. Inédito, depositado en la DXPC

CONESA FERNÁNDEZ-VíTORA, V. (1995) Guía metodológica para la Evaluación de Impacto Ambiental. Bilbao: Ediciones Mundi-Prensa, 1995

CRIADO BOADO, F.; GONZÁLEZ MÉNDEZ, M. (1993) La socialización del patrimonio arqueológico desde la perspectiva de la arqueología del paisaje. Actas del XXII Congreso Nacional de Arqueología. Vol. I, p. 261-266 
9. La arqueóloga R. Varela controla el desbroce superficial de la vegetación de un túmulo

10. Desbroce superficial para la localización de un túmulo prehistórico

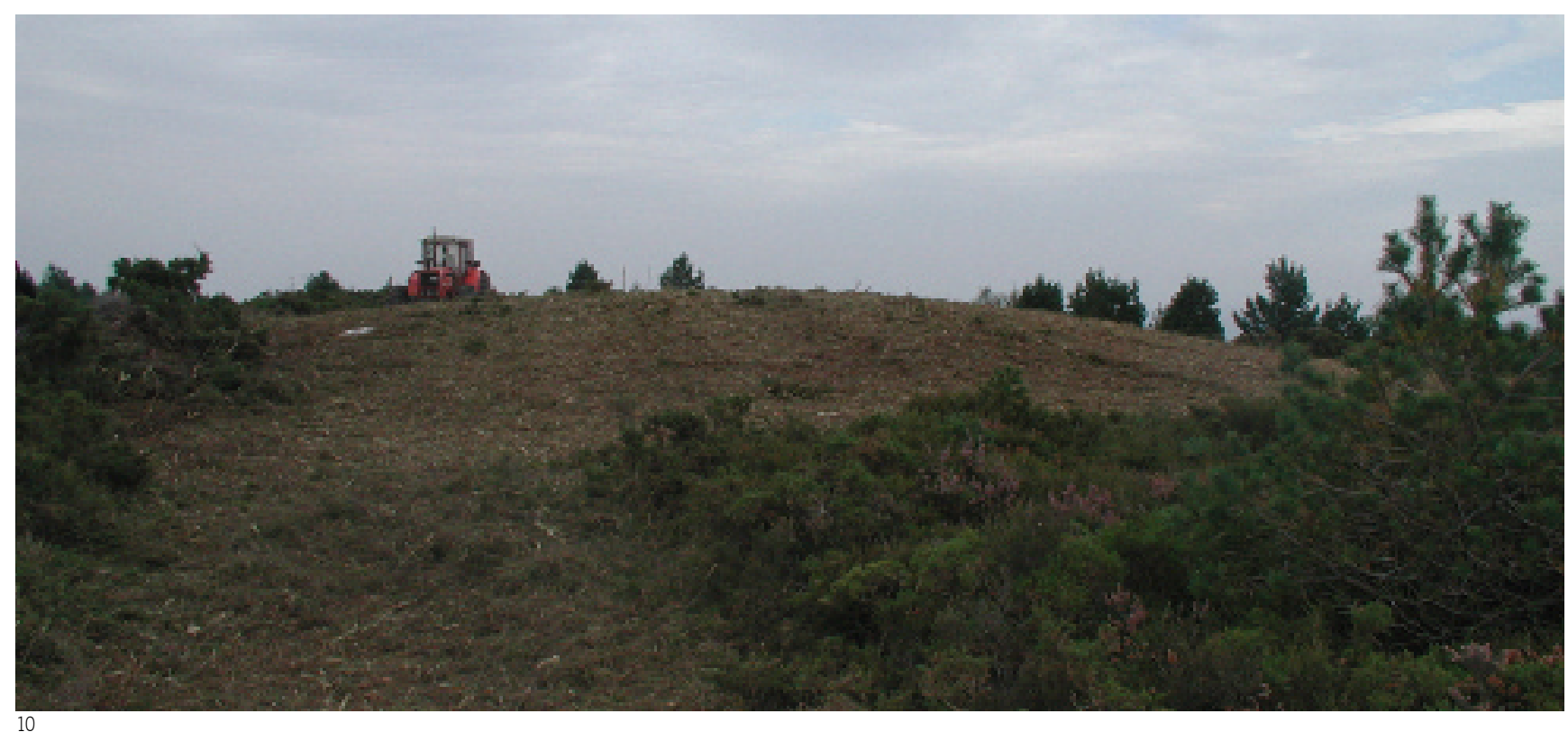

CRIADO BOADO, F. (1993) Limites y posibilidades de la Arqueologia del paisaje. SPAL, Revista de Prehistoria y Arqueología 2, p. 9-55

CRIADO BOADO, F. (1996b) La Arqueología del futuro, ¿el Futuro de la Arqueología? Trabajos de Prehistoria 53, ${ }^{\circ} 1$, p. 4-7

CRIADO BOADO, F. (1996c) La Arqueología del Paisaje como programa de gestión integral del Patrimonio Arqueológico. Boletín del Instituto Andaluz del Patrimonio Histórico, $n^{\circ} 14$, p.15-9

CRIADO BOADO, F. (1996d) Hacia un modelo integrado de investigación y gestión del Patrimonio Histórico: la cadena interpretativa como propuesta. PH: Boletín de IAPH, 1996, n 16, p. 73-8

CRIADO BOADO, F. (1999) Del terreno al Espacio: Planteamientos y perspectivas para la Arqueología del Paisaje. Criterios e Convencións en Arqueoloxía da Paisaxe, 6. Santiago de Compostela: LAFC, 1999

CRIADO BOADO, F.; VILLOCH VÁZQUEZ, V.; BARREIRO MARTÍNEZ, D. (2000) Arqueologia y Parques Eólicos en Galiza: Proyecto Marco de Evaluación de Impacto. Criterios e Convencións en Arqueoloxía da Paisaxe, 5. Santiago de Compostela: LAFC, 2000

GÓMEZ OREA, D. (1994) Evaluación de Impacto Ambiental. Madrid: Editorial Agrícola Española, 1994

GONZÁLEZ MÉNDEZ, M. (1999) Investigación y puesta en valor del Patrimonio Histórico: planteamiento y propuestas desde la Arqueología del Paisaje. Humanidades y Ciencias Sociales 1999. Tesis doctorales en CDRom. Santiago: Universidad de Santiago de Compostela

GONZÁLEZ MÉNDEZ, M. (2002) Promoción Social del pasado y geoarqueología. IV Reunión Nacional de Geoarqueología. Almazán. Soria, octubre 2002

GULLÓN MUÑóZ-REPISO, N.; ARCE RUIZ, R. M. (2002) La Evaluación Ambiental Estratégica de Planes y Programas de Infraestructuras. I Congreso de Ingeniería Civil, Territorio y Medio Ambiente Vol. I. Madrid, 2002
LÓPEZ CORDEIRO, M. M. (2003) Excavación de Sondeos Arqueológicos en el Parque Eólico Ampliación Álave-Soán (Muras y 0 Valadouro, Lugo). Informe Valorativo. Memoria Técnica. Inédito. Depositado en la DXPC

OREJAS SACO DEL VALLE, A. (1998) El Estudio del Paisaje: visiones desde la Arqueología. Arqueología Espacial n 19-20, p. 9-19

OREJAS SACO DEL VALLE, A. (2001) Los Parque Arqueológicos y el Paisaje como Patrimonio. ArkeoWeb (en línea) n 3 (1), 2001. www.ucm.es/info/arqueoweb/ numero3_1/conjunto3_1.htm (consulta: 06/03/2004)

RODRÍGUEZ TEMIÑO, I. (1998) Nuevas perspectivas en la protección del patrimonio arqueológico en el medio rural. Complutum nº 9, p. 298-310

RÖSSLER, M. (1998) Los paisajes culturales y la Convención del Patrimonio Mundial Cultural y Natural. Paisajes Culturales en los Andes. Memoria Narrativa, Casos de Estudio, Conclusiones y Recomendaciones de la Reunión de Expertos (en línea). www.condesan.org/unesco/paisajes_culturales_andes.htm (consulta: $10 / 06 / 04$

VILLOCH VÁZQUEZ, V. (2000) Estudio de Impacto Arqueológico Parque Eólico de Soán, Memoria Técnica. Inédito, depositado en la DXPC

VILLOCH VÁZQUEZ, V. (2000) Estudio de Impacto Arqueológico Parque Eólico de Fonsagrada, Memoria Técnica. Inédito, depositado en la DXPC

VILLOCH VÁZQUEZ, V.; BARREIRO MARTÍNEZ, D. (1997) ¿Arqueología vs. energía eólica?. Boletín del Instituto Andaluz del Patrimonio Histórico n² 20, 1997 , p.103-108

VILLOCH VÁZQUEZ, V.; BARREIRO MARTÍNEZ, D. (2001) La gestión medioambiental ante el patrimonio cultural. II Congreso galego da Calidade. Santiago de Compostela, 2-3 abril, 2001

VV.AA. (1995) Actas del XXII Congreso Nacional de Arqueología, I (Vigo, 1993). Vigo: Consellería de Cultura/Concello de Vigo, 1995 